
\title{
is Research Suare
}

\section{Loss of a Single Plant Functional Group in Litter Had Marginal Impacts on Microbial Community Diversity and Composition in a Tibet Fir Forest}

\section{Qianwei Li}

Sichuan Agricultural University

Lifeng Wang

Sichuan Agricultural University

Yamei Chen

China West Normal University

Li Guo

Sichuan Agricultural University

Chengming You

Sichuan Agricultural University

\section{Lixia Wang}

Sichuan Agricultural University

Han Li

Sichuan Agricultural University

Li Zhang

Sichuan Agricultural University

Bo Tan

Sichuan Agricultural University

Zhenfeng Xu

Sichuan Agricultural University

Jian Zhang

Sichuan Agricultural University

Yang Liu ( $\sim$ sicauliuyang@163.com )

Sichuan Agricultural University https://orcid.org/0000-0002-4795-9169

\section{Research Article}

Keywords: plant functional groups, litter decomposition, initial litter quality, microbial structure

Posted Date: July 30th, 2021

DOl: https://doi.org/10.21203/rs.3.rs-693895/v1

License: @ (i) This work is licensed under a Creative Commons Attribution 4.0 International License. Read Full License 


\section{Abstract}

Aim The decomposition of plant residues is a fundamental process of soil organic matter accumulation. The loss of plant functional groups (PFGs) could affect this process by producing litter of different qualities in the soil. Microorganisms are one of the indispensable driving forces of ecological processes, but the mechanisms by microbial communities respond to aboveground PFG changes are still unclear, which limits our understanding of biogeochemical cycle changes under PFG loss.

Methods We assessed the microbial taxonomic and functional composition of six typical single PFGs (evergreen conifer, evergreen shrubs, deciduous shrub, graminoid, forb and fern), random loss of a single PFG (SPFG) from litter mixtures and total mixture of six PFGs in a Tibetan fir forest by a high-throughput sequencing method.

Results The microbial composition and function did not change with loss of a SPFG in litter, and microbial communities were mainly determined by the carbon and nitrogen ratio (C:N), carbon and phosphorus ratio (C:P), N and lignin, and bacterial functional pathways and fungal functional guilds were both determined by $\mathrm{N}, \mathrm{C}: \mathrm{N}$ and $\mathrm{C}: \mathrm{P}$ ratios. Bacterial diversity was positively related while fungal diversity was negatively related to $\mathrm{N}$ and cellulose concentrations

Conclusion We speculated that the difference in initial litter qualities (especially $\mathrm{C}: \mathrm{N}$ ) between different PFGs, rather than a decreased number of PFGs, is a determinant of microbial composition and function. As the loss of PFG does not change litter quality, the microbial community can resist the loss of PFG, which maintains alpine ecosystem carbon and nutrient cycling stability.

\section{Introduction}

Litter decomposition is the key process in the material cycle of terrestrial ecosystems (Berg and Mcclaugherty, 2014), as it links terrestrial primary productivity with soil organic matter dynamics (Wang et al., 2019), affects ecosystem carbon storage and potentially exerts long-term impacts on climate (Chapin et al., 2002). Global warming has a major influence on global ecosystems and biodiversity (Loreau, 2010), including species loss in different trophic groups (Soliveres et al., 2016). Because litter decomposition is affected by changes in biodiversity at multiple trophic levels (including plants, microbial decomposers and varied invertebrate consumers) (Gessner et al., 2010), loss of biodiversity in terrestrial ecosystems due to global climate change may have a major impact on litter decomposition. In general, terrestrial ecosystems consist of a variety of plant species and plant functional groups (PFGs). Similarly, litter decomposition in the natural state always includes multiple species; hence, mixed litter degradation cannot be simply characterized by single leaf litter decomposition patterns (Gessner et al., 2010; Wardle et al., 1997; Blair et al., 1990). Therefore, experiments to understand the mechanism of litter decomposition in response to plant diversity change have been performed by mixing litters at the species level (Gartner and Cardon, 2004; Ball et al., 2008; Porre et al., 2020; Wang et al., 2020). However, a weakness of these studies is that plant species diversity often does not adequately reflect functional attributes, and deficiencies in single plant functional groups (SPFGs) have a greater impact on the ecosystem than the loss of the same number of species from different PFGs (Díaz and Cabido, 2001). For example, a litterbag experiment in grasslands showed that changes in plant functional diversity rather than species richness are critical to predicting the interaction between biodiversity and decomposition (Scherer-Lorenzen, 2008). Indeed, the loss of key functional groups may permanently alter the characteristics of ecosystems through changes in resource availability (Chapin et al., 2002). Thus, these studies of the loss of PFGs are important to understand how global climate change affects ecosystem function by influencing nutrient return.

Microorganisms are the most important decomposers that drive terrestrial biogeochemical cycles. Soil microbes degrade lignin, cellulose, hemicellulose, pectin and proteins in litter by secreting numerous enzymes, representing an indispensable part of carbon and nutrient cycling (Yadav and Malanson, 2007; Schneider et al., 2012; Berge and McClaugherty, 2014; Burns et al., 2002). Litter physicochemical properties vary with plant species (Porre et al., 2020), and litter nutrient concentration and carbon quality strongly influence microbial community composition and abundance (Aerts, 1997; Yan et al., 2018; Liu et al., 2020). Thus, it is necessary to investigate how microbial communities respond to changes in PFGs. It has been reported that litter traits drive the differentiation of microbial communities (Zheng et al, 2018). Furthermore, most microbes preferentially use litter materials rich in labile compounds and nutrients (Gessner et al., 2010), but bacteria may be more important for degrading organic materials with higher nitrogen concentrations (Six et al., 2002). In contrast, fungi tend to decompose organic materials with lower nitrogen concentrations (Frey et al., 1999; Guggenberger et al., 1999; Pascoal and Cássio, 2004). Additionally, different microbial species also have a preference for decomposition substrates. For example, Acidobacteria and Solibacteres prefer to use lignin, whereas Ascomycota prefer to use cellulose and hemicellulose (Wang et al., 2019). Nevertheless, there is no consistent conclusion regarding the response of the microbial community to changes in plant diversity due to the complex influences of plant diversity on the nutrient release of litter decomposition (Li et al., 2016), and whether and how PFG loss alters the structure, composition and microbial community remain poorly understood.

To better understand the relationship between plant diversity and ecosystem processes, we simulated single PFG litter loss through litterbag experiments to determine whether SPFG deficiencies in litter affected microbial community composition and function in a Tibetan fir forest. Therefore, we performed an experiment in the alpine fir forest of western Sichuan located in the upper reaches of the Yangtze River, which is located at the eastern margin of the QinghaiTibet Plateau and is sensitive to global climate change (IPCC, 2014). SPFG litter treatments and SPFG-loss litter treatments were conducted, bacterial and fungal community composition were monitored, diversity and function were determined using high-throughput sequencing, and the impact of initial litter quality on bacterial and fungal community structure and function was assessed. We hypothesize that (1) SPFG deficiencies would decrease bacterial and fungal community structure and function by changing nutrient availability and (2) the initial nitrogen and carbon concentrations in litter would greatly affect bacterial and fungal community structure and function.

\section{Materials And Methods}

\section{Study site}


The experimental site was located at the Long-Term Research Station of Alpine Forest Ecosystems of Sichuan Agricultural University ( $31^{\circ} 51^{\prime} 48^{\prime \prime}-31^{\circ} 51^{\prime} 53^{\prime \prime} \mathrm{N}$, $102^{\circ} 41^{\prime} 32^{\prime \prime}-102^{\circ} 41^{\prime} 54^{\prime \prime} E$, approx. 3900-4200 m a.s.I.) in the Zhegu Mountain region, which is located on the eastern edge of the Tibetan Plateau in Sichuan Province, China (Liu et al., 2019b; Zheng et al., 2020). This research area has a typical alpine climate. According to the data from alpine meteorological stations, the annual mean temperature is approximately $2.9^{\circ} \mathrm{C}$, the mean annual precipitation is approximately $870 \mathrm{~mm}$ in the alpine treeline station, and the period of snow cover is from October to April of the following year. The soils in the coniferous forest are classified as Cambisols and Histosol (World Reference Base taxonomy). This mountain exhibits remarkable vertical zonality from the valley to the hilltops, including a mixed coniferous-broadleaf forest, a dark coniferous forest (3900-4000 m a.s.I.), alpine shrubland (4000-4200 m a.s.I.), alpine meadow (>4200 m a.s.l.), and alpine desert (above $4500 \mathrm{~m}$ a.s.I.). Three permanent sites (50-m-wide transect) were established in 2012 as described by Liu et al. (2019b). This study was conducted in a coniferous forest (3900-4000 m a.s.I.) that was dominated by Abies faxoniana. The dominant shrub species included Rhododendron lapponicum, Salix paraplesia, and Sorbus rufopilosa; the dominant graminoid species included Poa crymophila and Deyeuxia scabrescens; the dominant forb species included Epilobium angustifolium and Ligularia sagitta; and the dominant fern species was Cystopteris montana (Chen et al. 2018; Liu et al. 2019a; Zheng et al. 2020).

\section{Experimental design and sample collection}

On the basis of previous studies (Chapin et al., 1996; Aerts, 2006), the representative plant species in the area were classified as follows: evergreen coniferous (Abies faxoniana, EC), evergreen shrub (Rhododendron lapponicum, ES), deciduous shrub (Sorbus rufopilosa, Salix paraplesia, DS), graminoid (Poa crymophila, Deyeuxia scabrescens, GR), forb (Epilobium angustifolium, Ligularia sagitta, FO), and fern (Cystopteris montana, FE), corresponding to a total of six PFGs.

In October 2015, we collected fresh foliar litter from the above six representative PFGs (Table S1). Fresh foliar litter was taken back to the laboratory, air-dried for two weeks, and then mixed to obtain a homogeneous sample. A total of 13 treatments were performed for these six PFGs, including (1) mixed litter from all six PFGs (total mixture, TM), (2) six single-SPFG treatments (i.e., EC, ES, DS, GR, FO and FE), and (3) six SPFG-loss treatments: mixed litter without EC (EC0), without ES (ESO), without DS (DS0), without GR (GR0), without FO (FO) and without FE (FEO) (Table S2). Twelve-gram subsamples of the air-dried litter were placed in each nylon litterbag $(20 \mathrm{~cm} \times 25 \mathrm{~cm}$, mesh size $1.0 \mathrm{~mm}$ ) (Guo et al., 2006). Of note, each PFG had the same weight when the number of PFGs was > 1. In addition, when representative species in the PFGs were $>1$, each plant species had the same weight. On 26 November 2015 , the litterbags ( 3 duplicates $\times$ 13 PFGs = 39 samples) were placed on top of the litter layer in the coniferous forest with at least 5-cm intervals between the litterbags. On 25 September 2017 , three litterbags for each PFG were collected and transported to the laboratory, where the soil and roots were removed from the litter. These samples were used for litter DNA extraction and stored at $-80^{\circ} \mathrm{C}$. The initial litter qualities (i.e., C, N, P, DOC, TDN, TDP, cellulose, lignin) used in this paper were determined by Chen et al. (2021).

\section{DNA extraction, PCR amplification and Illumina MiSeq sequencing}

Microbial DNA was extracted from 39 samples using the MN NucleoSpin 96 Soil Kit (Macherey-Nagel, Germany) according to the manufacturer's instructions. The V3-V4 region of the bacterial 16S rRNA gene was amplified with universal primers 338F (5'- ACTCCTACGGGAGGCAGCA-3') and 806R (5'GGACTACHVGGGTWTCTAAT-3') (Xu et al., 2016). The ITS1 region of the fungi was amplified with the forward primer ITS1F (5'-

CTTGGTCATTTAGAGGAAGTAA-3') and reverse primer ITS1R (5'-GCTGCGTTCTTCATCGATGC-3') (Sun et al., 2014) using a thermal cycler PCR system (Veriti 9902, AB, USA). The PCRs were conducted as follows: an initial denaturation, 25 cycles (second round, 10 cycles) of annealing and elongation, and a final extension. The amplified products were purified and recovered using a 1.8\% agarose gel electrophoresis method. The 16S rRNA and ITS1 gene amplicons were sequenced using Illumina HiSeq deep sequencing at Biomarker Bioinformatics Technology Co., Ltd. (Beijing, China).

\section{Processing of sequencing data}

To obtain the raw tags, paired-end reads were merged by FLASH v.1.2.11 (Magoč and Salzberg, 2011). To obtain clean tags, raw tags were then quality-filtered by Trimmomatic v.0.33. The reads were truncated at any site to obtain an average quality score $<20$ over a 50-bp sliding window (Bolger et al., 2014), and possible chimaeras were then identified by employing the UCHIME algorithm (Edgar et al., 2011). Operational taxonomic units (OTUs) were defined at the 97\% sequence similarity level by UCLUST v.10.0 (Edgar, 2013). The taxonomic assignment of the gene sequences was analysed using the RDP Classifier algorithm (v2.2, http://sourceforge.net/projects/rdpclassifier/) (Wang et al., 2007) against the databases of Silva 16S rRNA (Quast et al., 2013) and Unite ITS (Kõljalg et al., 2013), with a confidence threshold of $80 \%$. Alpha diversity (Shannon and Simpson diversity indices, Ace richness and Chao 1 richness estimators) was determined using Mothur v.1.30 (Schloss et al., 2009). PICRUST was used to predict the bacterial functional gene composition (Parks et al., 2014). FUNGuild (fungal functional guild) was used to parse fungal OTUs using an ecological guild taxonomy (Nguyen et al., 2016), and the guild with the highest probable confidence ranking was used for further statistical analyses.

\section{Statistical analyses}

Except when constructing rarefaction curves, the number of sequences per sample was normalized before analysis, and the sequences of unidentified taxa of the top 10 bacteria and fungi according to relative abundance were removed from the analyses. Furthermore, the microbial taxa of our sequencing results showed optimal resolution at the "class" level (Table S4); thus, we used it in the following analyses. Nonmetric multidimensional scaling (NMDS) and heat maps were examined using the Quantitative Insights into Microbial Ecology (QIIME) workflow (Caporaso et al., 2010). NMDS based on binary Jaccard similarity was performed to visually assess whether differences in bacterial or fungal community composition were present among the SPFG 
treatments, TM, and SPFG-loss treatments, and the significance of the observed differences was determined by analysis of similarities (ANOSIM) based on binary Jaccard. The similarities and shifts in the relative abundance of the top 10 bacterial and fungal classes are displayed as a heat map.

One-way analysis of variance (ANOVA) was used to evaluate the effects of different PFGs (i.e., TM and SPFG treatments) and loss of different SPFGs (i.e., TM and SPFG-loss treatments) on the relative abundance of the top 2 bacterial and fungal phyla and the top 9 identified bacterial and fungal classes and alpha diversity. The Student-Newman-Keuls (S-N-K) test was used to compare the means at a $95 \%$ confidence interval. The correlations between the alpha diversity and the initial litter quality parameters were analysed by the Pearson method. These statistical analyses were performed using SPSS Statistics for Windows version 25.0 (SPSS Inc., USA). The Mantel test based on binary Jaccard similarity was used to study the relationship between bacterial and fungal community similarities and initial litter quality parameters (correlations were considered significant at $p \leq 0.05$ using 9999 permutations). To evaluate the differences in bacterial functional metabolism and fungal functional guilds between the two groups, we employed a t-test using STAMP software (Parks et al., 2014), and the Benjamini-Hochberg FDR was used for multiple test correction. The relationships between initial litter quality parameters and the relative abundance of bacterial and fungal communities or bacterial functional metabolism and fungal functional guilds were analysed by redundancy analysis (RDA) (Canoco 4.5 software, Microcomputer Power, USA). The significance of the RDA results was assessed by a Monte Carlo permutation test ( $p<0.001)$. Notably, only one sample library was built successfully for FO, and two sample libraries were built successfully for FEO; thus, both the OTU data of FE and FOO were filtered in the analyses, which included ANOVA of the relative abundance and alpha diversity of microbial communities as well as the Mantel test.

\section{Results}

\section{Shifts in microbial diversity}

We obtained 2,027,900 high-quality 16S rDNA and 2,292,923 high-quality ITS rDNA sequences from the 36 samples, with an average of 56,331 16S rDNA and 63,692 ITS rDNA sequences in each sample. In general, the rarefaction curves tended to approach saturation, indicating that the amount of sequencing data was reasonable (Fig. S1).

The diversity indices (Shannon, Simpson) and the richness indices (Ace, Chao1) of each sample were calculated with 0TU clustering at 97\% sequence similarity. For bacteria, one-way ANOVA showed that the Shannon index was significantly different among the SPFG samples and TM. Specifically, the Shannon indices of DS, GR and FE were different from those of EC and ES, and those of DS and FE were significantly higher than those of TM (Table 2). For fungi, the Shannon and Simpson indices were significantly different among the SPFG samples and TM. Specifically, the Shannon index of ES of ES was different from that of other SPFG samples and TM, and there was a difference in the Simpson index between all of the SPFG samples and TM. Importantly, the diversity and richness indices of the bacterial and fungal communities were not significantly different between any of the SPFG-loss samples and TM (Table 2).

\section{Bacterial and fungal community structure}

For bacteria, a total of 182 shared bacterial species were detected among the SPFG samples and TM, while 3, 1, 2, 3, and 1 unique species were detected in EC, ES, DS, GR and TM, respectively (Fig. 1a1). A total of 209 shared bacterial species were detected among the SPFG-loss samples and TM, and only 1 exclusive bacterial species was detected in GR0 (Fig. 1a2). For fungi, a total of 42 shared fungal species were detected among the SPFG samples and TM, 1 unique species was detected in ES, and 1 unique species was found in TM, in addition to the shared species (Fig. 2a1). A total of 47 shared fungal species were detected among the SPFG-loss samples and TM (Fig. 2a2). The ANOSIM analysis showed that the similarity within the SPFG samples and TM (the R value for bacteria was 0.301 , and that for fungi was 0.423 ) was lower than that within the SPFG-loss samples and TM (the R value for bacteria was 0.084 , and that for fungi was 0.017 ) (Table 1). Furthermore, the NMDS plots indicated that the bacterial community structures in EC and ES and the fungal community structures in the ES differed from those in TM (Fig. 1c, Fig. 2c).

At the phylum level, all the bacteria in the litter samples were identified and grouped into 24 phyla (Table S4). The dominant bacterial phyla were Proteobacteria (54.6\%-67.7\%) and Bacteroidetes (13.8\% - 23.4\%) in thirteen PFGs, and there was no significant difference between the PFGs (Fig. 1b1, Table S5). At the class level, a total of 45 bacterial taxa were identified (Table S4). The top ten classes constituted $90.1 \%$ to $98.7 \%$ of the total population (one of them was an unidentified bacterium), and Alphaproteobacteria (33.4\%-44.3\%), Gammaproteobacteria (19.7\%-33.6\%) and Sphingobacteriia (9.6\%-17.7\%) predominated, followed by Actinobacteria, Betaproteobacteria, Flavobacteriia, Cytophagia, Acidobacteria and Spartobacteria (Fig. 1b2). Among them, one-way ANOVA showed that there was a difference in the relative abundance of some bacterial classes between some SPFG samples. Specifically, EC differed from other SPFG samples (Alphaproteobacteria, Gammaproteobacteria and Acidobacteria); ES differed from GR (Betaprotebacteria); FE differed from ES (Flavobacteriia); EC and ES differed from DS, GR and FE (Cytophagla); and DS differed from other SPFG samples

(Spartobacteria). The relative abundances of Alphaproteobacteria, Gammaproteobacteria and Acidobacteria in EC, Flavobacteriia in ES, Cytophagia in GR and FE, and Spartobacteria in DS differed from those in TM (Fig. 3). In the SPFG-loss sample, the relative abundances of Alphaproteobacteria and Flavobacteriia in DSO were different from those in TM.

A total of $95.0 \%$ fungal taxa were identified at the phylum level and grouped into 8 phyla (Table S4), and there were no significant differences in the relative abundances of the dominant phyla, i.e., Ascomycota (74.5\%-93.1\%) and Basidiomycota (2.3\%-10.1\%), among these PFGs (Fig. 2b1, Table S5). At the class level, a total of 24 fungal taxa were identified (Table S4). The top ten classes constituted $53.9 \%-95.1 \%$ of the total population (one of them was unidentified), and Leotiomycetes (26.7\%-75.1\%) was predominant, followed by Sordariomycetes (2.9\%-27.0\%), Dothideomycetes (4.1\%-15.0\%), and Tremellomycetes (1.0\%-6.3\%). The relative abundances of Pucciniomycetes, Microbotryomycetes, Agaricomycetes, Eurotiomycetes and Pezizomycotina_cls_Incertae_sedis were less than 1\% (Fig. 2b2). Among them, one-way ANOVA showed that there was a difference in some fungal classes between some SPFG samples. Specifically, 
ES differed from other SPFG samples (Leotiomycetes, Agaricomycetes and Eurotiomycetes); EC differed from other SPFG samples (Microbotryomycetes); GR differed from DS, FE and ES (Pezizomycotina_cls_Incertae_sedis); and Leotiomycetes, Agaricomycetes, Eurotiomycete and Pezizomycotina_cls_Incertae_sedis in ES were different compared with those in TM. However, there was no significant difference between any of the SPFG-loss treatments and TM treatment (Fig. 4).

\section{Bacterial community functions and fungal ecological functional guilds}

In this study, we identified eight metabolic functional pathways from bacteria. The most abundant functional pathway was amino acid transport and metabolism, followed by carbohydrate transport and metabolism and energy production and conversion, and the relative abundances of these three functional pathways reached over $50 \%$ (Fig. 5c). The proportions of metabolic function between some SPFG samples significantly differed according to pairwise comparisons by t-test (i.e., DS and ES, EC and ES, EC and FE, ES and FE, ES and GR) (Fig. S2a). Furthermore, the results of the t-test indicated that the proportions of metabolic functional pathways of FE, ES and EC were significantly different compared with those of TM, and in the SPFG-loss samples, only the proportions of carbohydrate transport and metabolism in GRO were higher than those in TM (Fig. 5a).

Based on fungal functional guild classifications, we distinguished two trophic modes (pathotrophs and saprotrophs), including 11 identified guilds and 1 unidentified guild, and the average relative abundance of unidentified saprotrophs in all PFGs was over $90 \%$ (Fig. 5d). Additionally, according to the t-test analysis, the proportions of fungal functional guilds of some PFGs significantly differed when analysed in pairwise comparisons (i.e., DS and ES, EC and ES, EC and GR, ES and GR, ES and FE, ES and TM, FEO and FOO) (Fig. 5d, Fig. S2b).

\section{Relationships between the bacterial community and initial litter quality}

The Shannon index was positively correlated with the concentrations of N and DOC $(p<0.05)$, and the Simpson index was negatively correlated with the concentration of $\mathrm{N}$ (Table S5).

The Mantel test showed that the concentrations of $\mathrm{N}$, cellulose, and lignin and the ratios of $\mathrm{C}: \mathrm{N}$ and $\mathrm{C}: \mathrm{P}$ in litter were significantly correlated with the structures of the bacterial community (Table 3). The RDA results indicated that for the composition of bacteria, the first two axes explained $53.5 \%$ of the variability (RDA ${ }_{1}$, the $\mathrm{x}$-axis for $46.5 \%$, and $\mathrm{RDA}_{2}$, the $\mathrm{y}$-axis for $7.0 \%$ ). The concentrations of the ratios of C:N and C:P, N, lignin, P, cellulose, TDP, TDN and DOC significantly influenced the bacterial community composition (Fig. 6a). Notably, Alphaproteobacteria and Gammaproteobacteria were the dominant classes, Alphaproteobacteria was positively affected by the C:P ratio, and Gammaproteobacteria was negatively affected by the C:P ratio. Flavobacteriia, Spartobacteria and Cytophagia were positively correlated with N, P, DOC, TDP, TDN and cellulose but were negatively correlated with lignin and the ratios of C:N and C:P. In addition, Betaproteobacteria and Acidobacteria were negatively correlated with N, P, DOC, TDN, TDP and cellulose but were positively correlated with lignin and the ratios of C:N and C:P.

Regarding bacterial community function, the first two axes explained $40.5 \%$ of the variability $\left(\mathrm{RDA}_{1}\right.$, the $\mathrm{x}$-axis for $39.7 \%$, and $\mathrm{RDA}$, the $y$-axis for $0.8 \%$ ). The concentrations of N, P, DOC, TDP and cellulose and the ratios of C:N and C:P significantly influenced the metabolic functional pathways of bacteria. In general, these eight metabolic functional pathways were negatively associated with the concentrations of N, P, DOC, TDP and cellulose but were positively associated with the ratios of C:N and C:P (Fig. 6c).

\section{Relationships between fungal community and initial litter quality}

The concentration of $\mathrm{N}$ was negatively associated with the Shannon and Chao1 indices, but the concentrations of N and DOC were positively associated with the Simpson index. The concentration of TDP was negatively associated with the Ace value (Table S5).

The Mantel test showed that the concentrations of N, P, and lignin and the ratios of C:N and C:P in litter were significantly correlated with the structures of fungal communities (Table 3). Regarding fungal community composition, the first two axes explained $31.2 \%$ of the variability (RDA 1 , the $x$-axis for $24.6 \%$, and $\mathrm{RDA}_{2}$, the $\mathrm{y}$-axis for 6.6\%). Leotiomycetes was the predominant class, and Agarcomycetes, Eurotiomycetes,

Microbotryomycetes and Pezizomycotina_cls_Incertae_sedis showed differences among these PFGs. Among

them, Leotiomycetes and Pezizomycotina_cls_Incertae_sedis were positively correlated with N, P, DOC, TDP and cellulose but negatively correlated with lignin and the ratios of C:N and C:P, whereas Agarcomycetes, Eurotiomycetes and Microbotryomycetes showed the opposite correlation with the initial litter qualities (Fig. 6b).

For the functional guilds of the fungal community, the first two axes explained $26.5 \%$ of the variability (RDA1, the $x$-axis for $17.5 \%$, and RDA2, the $y$-axis for $9.0 \%)$. The fungal functional guilds were significantly affected by the concentrations of N, lignin and P and the ratios C:N and C:P (Fig. $6 \mathrm{~d}$ ). Notably, lignin and the ratios of C:N and C:P were positively correlated with soil saprotrophs, pathogen-wood saprotrophs, ectomycorrhizal-undefined saprotrophs, dung saprotrophs, wood saprotrophs, animal pathogens and plant pathogens, while N and P were negatively correlated. However, undefined saprotrophs showed the opposite correlation with these initial litter qualities.

\section{Discussion}

\section{The impact of SPFG-loss on microbial community}

Page 5/16 
The marginal impact of SPFG deficiency on microbial community composition and function is contrary to the first hypothesis; there was no difference in the structures of the bacterial and fungal communities among the SPFG-loss samples and TM (Fig. 1c and d, Fig. 2c and d). We observed that loss of SPFG did not affect the structure and diversity of microbial communities in leaf litter in a short period, which was consistent with previous studies (Marshall et al., 2011; Zhang et al., 2011). These results may be due to the time-lag effect (Li et al., 2018). The response of ecosystem function to the loss of PFGs changes over time (Read et al., 2017), and the microbial community did not change significantly with changes in plant functional groups and abiotic factors when the experiment duration was relatively short. However, in this study, it can be seen from the diversity indices that the microbial community diversities of SPFGs were either the same as or higher than that of TM (Table 2). This finding may be attributed to the fact that the plant biomass inputs and productivity, rather than the diversity, of FPGs determined the microbial communities (Fanin et al., 2019). Furthermore, according to the mass ratio hypothesis (Grime, 1998), the characteristics of dominant plants, not species richness, have an impact on ecosystem properties. In this experiment, the diversity and composition of PFGs were changed, but the initial litter quality characteristics and biomass of leaf litter were not changed, which may result in resistance of microbial communities to SPFG loss.

\section{The relationship between initial litter quality and microbial community structure and diversity}

According to the initial litter qualities measured by Chen et al. (2021), we found that some initial litter quality parameters were different between the SPFG and TM treatments, but there was no significant difference in the concentrations of C, N, P, TDN, and TDP and the ratios of C:N and C:P between any of the SPFGloss treatments and TM treatment. The trend was similar to the variation in the microbial community among the different PFG treatments. Previous studies have indicated that the diversity indices and compositions of microbial communities in litter decomposition vary with litter quality (Malosso et al., 2004; Das et al., 2007; Zheng et al., 2018; Liu et al., 2019a). Indeed, we found that initial litter qualities had the opposite effect on the diversity of bacterial and fungal communities (Table S5). For instance, compared with the TM sample, the ES sample had higher lignin content and lower N and P contents, the DS samples had higher $\mathrm{N}$ and cellulose contents and lower lignin content, and the fungal diversity of ES and bacterial diversity of DS were both higher than those of TM (Table 2). Thus, we suggest that for the shift in microbial community diversity among PFGs, the difference in the initial litter parameter of PFGs is more important than the diversity of PFGs.

The RDA results indicated that the $\mathrm{C}: \mathrm{N}$ ratio was a determinant of bacterial and fungal community composition and function in litter after two years of decomposition. In addition, the $\mathrm{N}, \mathrm{P}$, cellulose, lignin and $\mathrm{C}: \mathrm{P}$ ratio were also important factors affecting microbial communities. For instance, the C:P ratio had a positive effect on Alphaproteobacteria but a negative effect on Gammaproteobacteria (Fig. 6a), and the EC treatment with the highest C:P ratio had the highest abundance of Alphaproteobacteria and the lowest abundance of Gammaproteobacteria (Fig. 3). In addition, Flavobacteriia require protein-based organic compounds (Bernardet, 2015); accordingly, the relative abundance of Flavobacteriia was positively affected by $\mathrm{N}$ but negatively affected by C:N (Fig. 6a). Chen et al. (2021) reported that there was no significant difference in initial litter quality among SPFG-loss and TM treatments. Hoorens et al. (2010) revealed that after mixing different PFGs, the positive and negative interactions balance each other. Thus, the similarity of chemical characteristics in mixed litters may be one of the reasons why the loss of SPFG does not change the structure and composition of the microbial community. However, the difference in initial C, N, and P stoichiometry among different SPFGs and TM resulted in a change in the relative proportion of dominant species in the microbial community. Overall, we hypothesized that in alpine ecosystems, the initial qualities of leaf litter based on PFG levels rather than the diversity of PFGs can be used as an important indicator to predict the microbial community response to vegetation community change in a short period.

\section{Changes in the prevalence of some functions of the microbial community}

First, in our study, the composition of microbial metabolic functional pathways of different PFGs did not change (Fig. $5 \mathrm{c}$ and d). While the functional composition of the microbial community is more similar than the microbial species composition under similar environmental conditions (Louca et al., 2016; Nelson et al., 2016), many microbes with different taxonomic units can perform the same metabolic function (Louca et al., 2018). Thus, the opposite responses of Alphaproteobacteria and Gammaproteobacteria to the difference in litter quality may be one of the reasons why metabolic function types were conserved among all PFG treatments in the subsequent analysis.

Second, amino acid transport and metabolism were the major metabolic pathways of the bacterial community, and saprotrophic fungi dominated the fungal community (Fig. 5c). Wang et al. (2019) revealed that bacteria are rich in amino acid metabolism genes and prefer organic materials with higher $\mathrm{N}$ concentrations (Six et al., 2002). Indeed, in all PFGs, Proteobacteria were the predominant bacteria and mainly decomposed proteins and amino acids (Schweitzer et al., 2001; Kazakov et al., 2009). Among fungi, saprotrophs are abundant in forest soil (Nguyen et al., 2016; Baldrian, 2017), and some saprotrophs (i.e., undefined saprotrophs, wood saprotrophs) and plant pathogens are the most represented taxa in decomposing wood (Kubartová et al., 2012; Ottosson et al., 2014). Saprotrophic fungi rely on plant-derived resources via litterfall and rhizodeposition and subsequently play the most important role in decomposition (Schmit and Mueller, 2007; Fanin et al., 2019; Schmidt et al., 2019). This group includes Ascomycota, which are the dominant fungi decomposing cellulose and hemicellulose (Pointing and Hyde, 2000; Sánchez, 2009; Zhang et al., 2016), which is consistent with our results.

Moreover, litter traits have impacts on microbial activity and substrate utilization, and microbial functional diversity is largely determined by resource availability (Hättenschwiler et al., 2005; Gionchetta et al., 2020). These RDA results supported the finding that the C:N ratio and $\mathrm{N}$ content drove the proportions of bacterial metabolic pathways and fungal ecological functional guilds (Fig. $6 \mathrm{c}$ and d). A high C:N ratio promoted the utilization of substrate nutrients by bacteria but inhibited the abundance of saprophytic fungi during decomposition. Nitrogen metabolism is the main method of material cycling in litter degradation. 


\section{Conclusion}

In conclusion, we found that the initial quality of litter drives changes in microbial community composition and functions. In particular, the initial C:N ratio was the most important factor controlling microbial community composition, structure and function, which affected the litter decomposition rate and nutrient cycling efficiency. At the same time, bacterial and fungal communities had opposite responses to the change in litter quality. A high C:N ratio promoted the utilization of nutrients by bacteria but inhibited the activities of fungal communities. The loss of SPFG did not change the initial quality, which may be one of the reasons why the composition and structure of the microbial community did not differ between the SPFG-loss and TM treatments. In addition, the opposite effect of initial litter quality on the dominant classes of bacterial or fungal communities may be the reason for maintaining the stability of metabolic pathway types and functional guilds of microbial communities among different PFGs. Thus, we suggest that the microbial community can resist the loss of a SPFG, which provided alpine ecosystem $\mathrm{C}$ and nutrient cycling stability to a certain extent. These findings can provide a better understanding of the link between above- and belowground ecosystems and valuable insights into the roles of microbes in litter decomposition in response to global climate change in alpine ecosystems.

\section{Declarations}

Funding: This work was financially supported by projects from the Science and Technology Development Project of the central government guided in Sichuan (2020ZYD049), National Natural Science Foundation of China (31570605), and the Key Project of Sichuan Education Department (18ZA0393).

Conflict of Interest: The authors declare that they have no conflicts of interest.

Availability of data and materials: All data included in this study are available upon request by contacting the corresponding author.

Code availability: Not applicable

Authors' contributions:

Qianwei Li: Formal analysis, Investigation, Data Curation, Writing - Original Draft, Writing - Review \& Editing, Visualization

Lifeng Wang: Formal analysis, Investigation, Data Curation

Yamei Chen: Conceptualization, Methodology, Formal analysis, Investigation, Data Curation, Writing - Review \& Editing, Supervision

Li Guo: Resources

Chengming You: Resources

Lixia Wang: Writing - Review \& Editing

Han Li: Resources

Li Zhang: Resources

Bo Tan: Resources

Zhenfeng Xu: Resources

Jian Zhang: Resources, Methodology, Funding acquisition

Yang Liu: Resources, Methodology, Writing - Review \& Editing, Project administration, Funding acquisition

\section{References}

1. Aerts R (1997) Climate, leaf litter chemistry and leaf litter decomposition in terrestrial ecosystems: a triangular relationship. Oikos 79(3):439

2. Aerts R (2006) The freezer defrosting: global warming and litter decomposition rates in cold biomes. J Ecol 94:713-724

3. Baldrian P (2017) Forest microbiome: diversity, complexity and dynamics. Fems Microbiol Rev 41:109-130

4. Ball BA, Hunter MD, Kominoski JS, Swan CM, Bradford MA (2008) Consequences of non-random species loss for decomposition dynamics: experimental evidence for additive and non-additive effects. J Ecol 96:303-313

5. Berg B, Mcclaugherty C (2014) Decomposition, humus formation, carbon sequestration. Springer, Berlin Heidelberg

6. Bernardet JF (2015) Flavobacteriales ord. nov, Bergey's Manual of Systematics of Archaea and Bacteria. John Wiley \& Sons, New Jersey, pp 1-2

7. Blair JM, Parmelee RW, Beare MH (1990) Decay rates, nitrogen fluxes, and decomposer communities of single-and mixed-species foliar litter. Ecology 71(5):1976-1985

8. Bolger AM, Marc L, Bjoern U (2014) Trimmomatic: a flexible trimmer for Illumina sequence data. Bioinformatics 30(15):2114-2120

9. Burns RG, Dick RP (2002) Enzymes in the environment: activity, ecology, and applications. CRC Press, New York

10. Caporaso JG, Bittinger K, Bushman FD, DeSantis TZ, Andersen GL, Knight R (2010) PyNAST: a flexible tool for aligning sequences to a template alignment. Bioinformatics 26(2):266-267 
11. Chapin FSI, Bret-Harte MS, Hobbie SE, Zhong H (1996) Plant functional types as predictors of transient responses of arctic vegetation to global change. J Veg Sci 7(3):347-358

12. Chapin FS, Matson PA, Mooney HA (2002) Principles of Terrestrial Ecosystem Ecology. Springer, New York

13. Chen Y, Liu Y, Zhang J, Yang W, He R, Deng C (2018) Microclimate exerts greater control over litter decomposition and enzyme activity than litter quality in an alpine forest-tundra ecotone. Sci Rep 8:14998. https://doi.org/10.1038/s41598-018-33186-4

14. Chen Y, Zhang J, Liu Y, Wang L, Zheng H (2021) Effects of single plant functional type loss on microbial community composition and litter decomposition in an alpine timberline ecotone. Eur J Soil Biol 104:103318

15. Das M, Royer TV, Leff LG (2007) Diversity of Fungi, Bacteria, and Actinomycetes on Leaves Decomposing in a Stream.Appl. Environ Microbiol 73(3):756767

16. Díaz S, Cabido M (2001) Vive la différence: plant functional diversity matters to ecosystem processes. Trends Ecol Evol 16(11):646-655

17. Edgar RC, Haas BJ, Clemente JC, Quince C, Knight R (2011) UCHIME improves sensitivity and speed of chimera detection. Bioinformatics 27:2194-2200

18. Edgar RC (2013) UPARSE: highly accurate OTU sequences from microbial amplicon reads. Nat Methods 10:996-998

19. Fanin N, Kardol P, Farrell M et al (2019) Effects of plant functional group removal on structure and function of soil communities across contrasting ecosystems. Ecol Lett 22:1095-1103

20. Frey SD, Elliott ET, Paustian K (1999) Bacterial and fungal abundance and biomass in conventional and no-tillage agroecosystems along two climatic gradients. Soil Biol Biochem 31:573-585

21. Gartner TB, Cardon ZG (2004) Decomposition dynamics in mixed-species leaf litter. Oikos 104(2):230-246

22. Gessner MO, Swan CM, Dang CK et al (2010) Diversity meets decomposition. Trends Ecol Evol 25(6):372-380

23. Gionchetta G, Oliva F, Romani AM, Baneras $L$ (2020) Hydrological variations shape diversity and functional responses of streambed microbes. The Sci Total Environ 714. https://doi.org/10.1016/j.scitotenv.2020.136838

24. Grime JP (1998) Benefits of plant diversity to ecosystems: immediate, filter and founder effects. J Ecol 86:902-910

25. Guggenberger G, Frey SD, Six J, Paustian K, Elliott ET (1999) Bacterial and fungal cell-wall residues in conventional and no-tillage agroecosystems. Soil Sci Soc Am J 63:1188-1198

26. Hättenschwiler S, Tiunov AV, Scheu S (2005) Biodiversity and litter decomposition in terrestrial ecosystems. Annu Rev Ecol Evol Syst 36:191-218

27. Hoorens B, Stroetenga M, Aerts R (2010) Litter mixture interactions at the level of plant functional types are additive. Ecosystems 13(1):90-98

28. IPCC (2014) Climate change 2014: synthesis report. Contribution of Working Groups I, II and III to the fifth assessment report of the Intergovernmental Panel on Climate Change. Cambridge University Press, Cambrige

29. Kazakov AE, Rodionov DA, Alm E et al (2009) Comparative Genomics of Regulation of Fatty Acid and Branched-Chain Amino Acid Utilization in Proteobacteria. J Bacteriol 191:52-64

30. Kõljalg U, Nilsson RH, Abarenkov K et al (2013) Towards a unified paradigm for sequence-based identification of fungi. Mol Ecol 22:5271-5277

31. Kubartová A, Ottosson E, Dahlberg A, Stenlid J (2012) Patterns of fungal communities among and within decaying logs, revealed by 454 sequencing. Mol Ecol 21:4514-4532

32. Li YN, Zhou XM, Zhang NL, Ma KP (2016) The research of mixed litter effects on litter decomposition in terrestrial ecosystems. Acta Ecol Sin 36(16):4977-4987

33. Li W, Zhang R, Liu S, Li W, Li J, Zhou H, Knops JMH (2018) Effect of loss of plant functional group and simulated nitrogen deposition on subalpine ecosystem properties on the Tibetan Plateau. Sci Total Environ 631-632:289-297

34. Liu Y, Shen X, Chen Y et al (2019a) Litter chemical quality strongly affects forest floor microbial groups and ecoenzymatic stoichiometry in the subalpine forest. Ann For Sci 76:106

35. Liu Y, Wang L, He R et al (2019b) Higher soil fauna abundance accelerates litter carbon release across an alpine forest-tundra ecotone. Sci Rep 9(1):10561

36. Liu Y, Zhu G, Hai X, Li J, Shangguan Z, Peng C, Deng L (2020) Long-term forest succession plant diversity and soil quality but not significantly increase soil microbial diversity: Evidence from the Loess Plateau. Ecol Eng 142:105631

37. Loreau M (2010) Linking Biodiversity and Ecosystems: Towards a Unifying Ecological Theory. Phil Trans R Soc B 365:49-60

38. Louca S, Parfrey LW, Doebeli M (2016) Decoupling function and taxonomy in the global ocean micobiome. Science 353:1272-1277

39. Louca S, Polz MF, Mazel F et al (2018) Function and functional redundancy in microbial systems. Nat Ecol Evol 2:936-943

40. Magoč T, Salzberg SL (2011) FLASH: fast length adjustment of short reads to improve genome assemblies. Bioinformatics 27(21):2957-2963

41. Malosso E, English L, Hopkins DW, O'Donnell AG (2004) Use of ${ }^{13} \mathrm{C}$-labelled plant materials and ergosterol, PLFA and NLFA analyses to investigate organic matter decomposition in Antarctic soil. Soil Biol Biochem 36:165-175

42. Marshal CB, McLaren JR, Turkington R (2011) Soil microbial communities resistant to changes in plant functional group composition. Soil Biol Biochem 43(1):78-85

43. Nelson MB, Martiny AC, Martiny JB (2016) Global biogeography of microbial nitrogen-cycling traits in soil. PNAS 113:8033-8040

44. Nguyen NH, Song Z, Bates ST et al (2016) FUNGuild: An open annotation tool for parsing fungal community datasets by ecological guild. Fungal Ecol 20:241-248

45. Ottosson E, Nordén J, Dahlberg A et al (2014) Species associations during the succession of wood-inhabiting fungal communities. Fungal Ecol 11:17-28 46. Parks DH, Tyson GW, Philip H, Beiko RG (2014) STAMP: statistical analysis of taxonomic and functional profiles. Bioinformatics 30(21):3123-3124

Page $8 / 16$ 
47. Pascoal C, Cássio F (2004) Contribution of fungi and bacteria to leaf litter decomposition in a polluted river. Appl Environ Microbiol 70:5266-5273

48. Pointing SB, Hyde KD (2000) Lignocellulose-degrading marine fungi. Biofouling 15:221-229

49. Porre RJ, van der Werf W, De Deyn GB, Stomp TJ, Hoffland E (2020) Is litter decomposition enhanced in species mixtures? A meta-analysis. Soil Biol Biochem 145:107791

50. Quast C, Pruesse E, Yilmaz P et al (2013) The SILVA ribosomal RNA gene database project: improved data processing and web-based tools. Nucleic Acids Res 41:590-596

51. Read QD, Henning JA, Classen AT, Sanders NJ (2017) Aboveground resilience to species loss but belowground resistance to nitrogen addition in a montane plant community. J Plant Ecol 11(3):351-363

52. Sánchez C (2009) Lignocellulosic residues: Biodegradation and bioconversion by fungi. Biotechnol Adv 27:185-194

53. Scherer-Lorenzen M (2008) Functional diversity affects decomposition processes in experimental grasslands. Funct Ecol 22:547-555

54. Schloss PD, Westcott SL, Ryabin T et al (2009) Introducing mothur: Open-Source, Platform-Independent, Community-Supported Software for Describing and Comparing Microbial Communities. Appl Environ Microbiol 75:7537-7541

55. Schmidt R, Mitchell J, Scow K (2019) Cover cropping and no-till increase diversity and symbiotroph:saprotroph ratios of soil fungal communities. Soil Biol Biochem 129:99-109

56. Schmit JP, Mueller GM (2007) An estimate of the lower limit of global fungal diversity. Biodivers Conserv 16:99-111

57. Schneider T, Keiblinger KM, Schmid E et al (2012) Who is who in litter decomposition? Metaproteomics reveals major microbial players and their biogeochemical functions. ISME J 6(9):1749-1762

58. Schweitzer B, Huber I, Amann R, Ludwig W, Simon M (2001) a- and $\beta$-Proteobacteria control the consumption and release of amino acids on lake snow aggregates. Appl Environ Microbiol 67:632-645

59. Six J, Feller C, Denef K, Ogle SM, Albrecht A (2002) Soil organic matter, biota and aggregation in temperate and tropical soils-Effects of no-tillage. Agronomie 22:755-775

60. Soliveres S, Van Der Plas F, Manning P et al (2016) Biodiversity at multiple trophic levels is needed for ecosystem multifunctionality. Nature 536:456-459. https://doi.org/10.1038/nature19092

61. Sun Z, Liu W, Bao Q, Zhang J, Hou Q, Kwok L, Sun T, Zhang H (2014) Investigation of bacterial and fungal diversity in tarag using high-throughput sequencing. J Dairy Sci 97:6085-6096

62. Wang Q, Garrity GM, Tiedje JM, Cole JR (2007) Naive Bayesian classifier for rapid assignment of rRNA sequences into the new bacterial taxonomy. Appl Environ Microbiol 73:5261-5267

63. Wang W, Chen D, Sun X, Zhang Q, Koide RT, Insam H, Zhang S (2019) Impacts of mixed litter on the structure and functional pathway of microbial community in litter decomposition. Appl Soil Ecol 144:72-82

64. Wang W, Zhang Q, Sun X, Chen D, Insam H, Koide RT, Zhang S (2020) Effects of mixed-species litter on bacterial and fungal lignocellulose degradation functions during litter decomposition. Soil Biol Biochem 141:107690

65. Wardle DA, Bonner KI, Nicholson KS (1997) Biodiversity and plant litter: experimental evidence which does not support the view that enhanced species richness improves ecosystem function. Oikos 79(2):247-258

66. Xu N, Tan G, Wang H, Gai X (2016) Effect of biochar additions to soil on nitrogen leaching, microbial biomass and bacterial community structure. Eur J Soil Biol 74:1-8

67. Yadav V, Malanson G (2007) Progress in soil organic matter research: litter decomposition, modelling, monitoring and sequestration. Prog Phys Geog $31: 131-154$

68. Yan J, Lei W, Yu H, Tsang Y, Ying S (2018) Plant litter composition selects different soil microbial structures and in turn drives different litter decomposition pattern and soil carbon sequestration capability. Geoderma 319:194-203

69. Zhang CB, Ke SS, Wang J, Ge Y, Chang SX, Zhu SX, Chang J (2011) Responses of microbial activity and community metabolic profiles to plant functional group diversity in a full-scale constructed wetland. Geoderma 160(3-4):503-508

70. Zhang L, Jia Y, Zhang X, Feng X, Wu J, Wang L, Chen G (2016) Wheat straw: An inefficient substrate for rapid natural lignocellulosic composting. Bioresour Technol 209:402-406

71. Zheng H, Chen Y, Liu Y et al (2018) Litter quality drives the differentiation of microbial communities in the litter horizon across an alpine treeline ecotone in the eastern Tibetan Plateau. Sci Rep 8:10029

72. Zheng H, Liu Y, Chen Y, Zhang J, Li H, Wang L, Chen Q (2020) Short-term warming shifts microbial nutrient limitation without changing the bacterial community structure in an alpine timberline of the eastern Tibetan Plateau. Geoderma 360:113985

\section{Tables}

Table 1 The similarity of microbial community composition analysis using analysis of similarities (ANOSIM) based on Binary-Jaccard 


\begin{tabular}{lllll} 
Treatment & \multicolumn{2}{l}{ Bacterial } & \multicolumn{2}{l}{ Fungi } \\
\cline { 2 - 5 } & $\mathrm{R}$ & $\mathrm{P}$ & $\mathrm{R}$ & $\mathrm{P}$ \\
\hline SPFGs & 0.301 & 0.004 & 0.423 & 0.004 \\
\hline loss SPFGs & 0.084 & 0.140 & 0.017 & 0.431
\end{tabular}

Table 2 Diversity and richness of bacterial and fungal communities at Class level among 13 plant functional groups (mean \pm SD).

\begin{tabular}{|c|c|c|c|c|c|c|c|c|c|}
\hline \multirow[t]{2}{*}{ Treatment } & \multirow[t]{2}{*}{ Group } & \multicolumn{4}{|l|}{ Bacteria } & \multicolumn{4}{|l|}{ Fungi } \\
\hline & & Shannon & Simpson & Ace & Chao1 & Shannon & Simpson & Ace & Chao1 \\
\hline & TM & $1.78 \pm 0.03 a b A$ & $0.25 \pm 0.01 \mathrm{aA}$ & $41.17 \pm 3.49 a \mathrm{~A}$ & $39.21 \pm 1.38 \mathrm{aA}$ & $0.78 \pm 0.31 \mathrm{aA}$ & $0.67 \pm 0.15 \mathrm{bA}$ & $21.07 \pm 2.29 a A$ & $17.78 \pm 0.64 a A$ \\
\hline \multirow[t]{7}{*}{ SPFGs } & $\mathrm{EC}$ & $1.71 \pm 0.08 a$ & $0.24 \pm 0.03 a$ & $37.17 \pm 1.64 a$ & $37.47 \pm 2.36 a$ & $1.02 \pm 0.03 a$ & $0.48 \pm 0.02 a b$ & $23.67 \pm 5.74 a$ & $20.50 \pm 3.33 a$ \\
\hline & ES & $1.72 \pm 0.01 \mathrm{a}$ & $0.27 \pm 0.01 a$ & $37.90 \pm 1.88 a$ & $38.14 \pm 1.71 \mathrm{a}$ & $1.61 \pm 0.02 b$ & $0.28 \pm 0.01 a$ & $22.40 \pm 0.97 a$ & $22.00 \pm 1.00 \mathrm{a}$ \\
\hline & DS & $1.95 \pm 0.03 c$ & $0.21 \pm 0.00 \mathrm{a}$ & $37.67 \pm 1.86 a$ & $37.52 \pm 1.77 a$ & $1.05 \pm 0.07 a$ & $0.44 \pm 0.04 a b$ & $20.33 \pm 3.69 a$ & $18.33 \pm 2.40 \mathrm{a}$ \\
\hline & GR & $1.89 \pm 0.03 b c$ & $0.22 \pm 0.01 a$ & $39.67 \pm 1.20 \mathrm{a}$ & $39.52 \pm 0.91 a$ & $0.80 \pm 0.08 a$ & $0.62 \pm 0.04 a b$ & $17.72 \pm 1.81 a$ & $17.17 \pm 2.05 a$ \\
\hline & FO & 1.99 & 0.22 & 44.0 & 55.0 & 1.23 & 0.46 & 26.08 & 25.00 \\
\hline & FE & $1.96 \pm 0.04 c$ & $0.21 \pm 0.02 a$ & $36.33 \pm 0.33 a$ & $36.49 \pm 0.29 a$ & $0.77 \pm 0.17 a$ & $0.63 \pm 0.11 a b$ & $29.41 \pm 2.55 a$ & $20.50 \pm 2.47 a$ \\
\hline & $\begin{array}{l}F \\
\text { value }\end{array}$ & $7.911^{\star *}$ & 2.056 & 0.544 & 0.809 & $4.589 *$ & $3.481^{*}$ & 1.514 & 0.754 \\
\hline \multirow{7}{*}{$\begin{array}{l}\text { loss } \\
\text { SPFGs }\end{array}$} & ECO & $2.00 \pm 0.03 \mathrm{~A}$ & $0.21 \pm 0.00 \mathrm{~A}$ & $38.83 \pm 0.44 \mathrm{~A}$ & $39.46 \pm 0.43 \mathrm{~A}$ & $0.80 \pm 0.08 \mathrm{~A}$ & $0.62 \pm 0.05 \mathrm{~A}$ & $17.83 \pm 1.43 \mathrm{~A}$ & $16.83 \pm 0.93 \mathrm{~A}$ \\
\hline & ESO & $1.79 \pm 0.04 \mathrm{~A}$ & $0.24 \pm 0.01 \mathrm{~A}$ & $35.90 \pm 1.02 \mathrm{~A}$ & $36.53 \pm 1.32 \mathrm{~A}$ & $1.03 \pm 0.15 \mathrm{~A}$ & $0.51 \pm 0.08 \mathrm{~A}$ & $18.92 \pm 1.47 \mathrm{~A}$ & $17.44 \pm 1.79 \mathrm{~A}$ \\
\hline & DSO & $2.00 \pm 0.22 \mathrm{~A}$ & $0.21 \pm 0.04 \mathrm{~A}$ & $39.00 \pm 1.00 \mathrm{~A}$ & $39.06 \pm 0.09 \mathrm{~A}$ & $0.88 \pm 0.37 \mathrm{~A}$ & $0.63 \pm 0.16 \mathrm{~A}$ & $20.89 \pm 1.43 \mathrm{~A}$ & $20.44 \pm 1.66 \mathrm{~A}$ \\
\hline & GRO & $2.04 \pm 0.06 \mathrm{~A}$ & $0.20 \pm 0.00 \mathrm{~A}$ & $39.33 \pm 0.88 \mathrm{~A}$ & $39.65 \pm 1.07 \mathrm{~A}$ & $0.76 \pm 0.27 \mathrm{~A}$ & $0.66 \pm 0.15 \mathrm{~A}$ & $20.72 \pm 1.07 \mathrm{~A}$ & $19.94 \pm 0.71 \mathrm{~A}$ \\
\hline & FOO & $2.04 \pm 0.07 \mathrm{~A}$ & $0.20 \pm 0.00 \mathrm{~A}$ & $38.28 \pm 1.30 \mathrm{~A}$ & $39.30 \pm 1.78 \mathrm{~A}$ & $0.94 \pm 0.59 \mathrm{~A}$ & $0.64 \pm 0.23 \mathrm{~A}$ & $17.52 \pm 2.07 \mathrm{~A}$ & $16.83 \pm 2.09 \mathrm{~A}$ \\
\hline & FEO & $1.85 \pm 0.17 \mathrm{~A}$ & $0.23 \pm 0.04 \mathrm{~A}$ & $36.13 \pm 2.88 \mathrm{~A}$ & $36.69 \pm 2.61 \mathrm{~A}$ & $0.66 \pm 0.11 \mathrm{~A}$ & $0.73 \pm 0.04 \mathrm{~A}$ & $19.88 \pm 7.12 \mathrm{~A}$ & $17.50 \pm 5.50 \mathrm{~A}$ \\
\hline & $\begin{array}{l}F \\
\text { value }\end{array}$ & 1.213 & 1.384 & 0.929 & 1.033 & 0.124 & 0.186 & 0.418 & 0.629 \\
\hline
\end{tabular}

TM: total mixture, EC: evergreen coniferous, ES: evergreen shrub, DS: deciduous shrub, GR: graminoid, FO: forb, FE: fern, ECO: the loss of evergreen coniferous, ESO: the loss of evergreen shrub, DSO: the loss of deciduous shrub, GRO: the loss of graminoid, FOO: the loss of forb, FE0: the loss of fern. Only one sample library was built successfully for FO. Lowercase letters indicate significant differences among single plant functional groups and TM, capital letters indicate significant differences among loss plant functional groups and TM as identified by the Student-Newman-Keuls Q test. One-way ANOVA * $p<0.05$; $* \star p<0.01$.

Table 3 Mantel test results analysis the bacterial and fungal community structures and initial litter quanlity paramteres

\begin{tabular}{lll} 
Initial litter qualities & Bacterial community & Fungal community \\
\hline $\mathrm{C}$ & 0.092 & -0.06 \\
\hline$N$ & $0.192^{*}$ & $0.310^{* *}$ \\
\hline $\mathrm{P}$ & 0.190 & $0.364^{* *}$ \\
\hline DOC & 0.112 & 0.059 \\
\hline TDN & -0.029 & -0.064 \\
\hline TDP & 0.013 & 0.067 \\
\hline Cellulose & $0.134^{*}$ & 0.052 \\
\hline Lignin & $0.207^{*}$ & $0.189 *$ \\
\hline C:N & $0.299^{*}$ & $0.377^{*}$ \\
\hline C:P & $0.290^{*}$ & $0.366^{*}$
\end{tabular}

Values in bold indicate statistical significance. Significance levels are shown at ${ }^{*} p<0.05$ and ${ }^{* \star} p<0.01$ based on Binary-Jaccard. C: carbon content, N: nitrogen content, P: phosphorus content, DOC: dissolved organic carbon, TDN: total dissolved nitrogen, TDP: total dissolved phosphorus, C:N the ratio of carbon and nitrogen, $\mathrm{C}: \mathrm{P}$ the ratio of carbon and phosphorus.

\section{Figures}



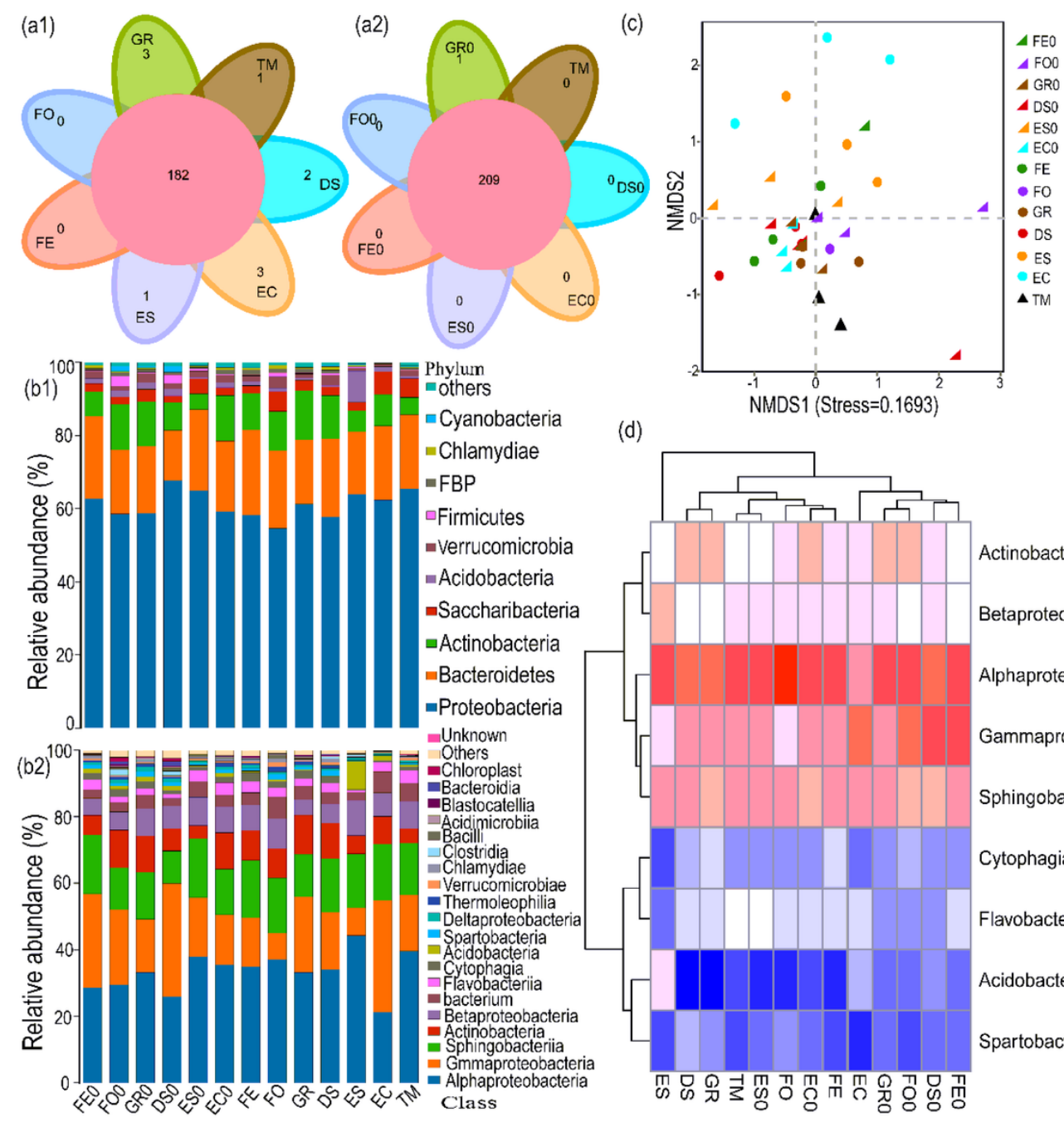

(d)

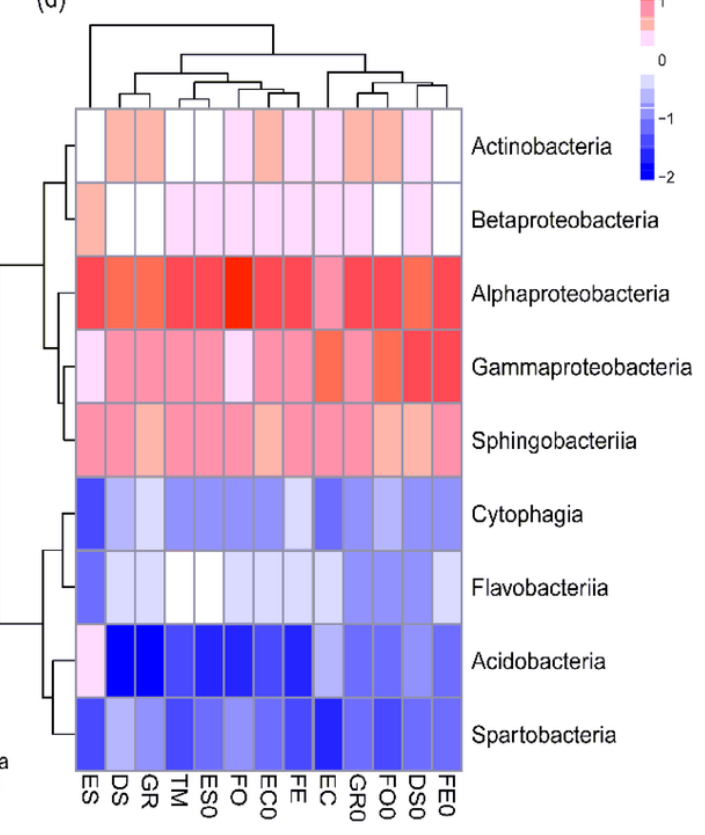

\section{Figure 1}

For bacteria, a total of 182 shared bacterial species were detected among the SPFG samples and TM, while $3,1,2,3$, and 1 unique species were detected in EC, ES, DS, GR and TM, respectively (Fig. 1a1). A total of 209 shared bacterial species were detected among the SPFG-loss samples and TM, and only 1 exclusive bacterial species was detected in GR0 (Fig. 1a2). 

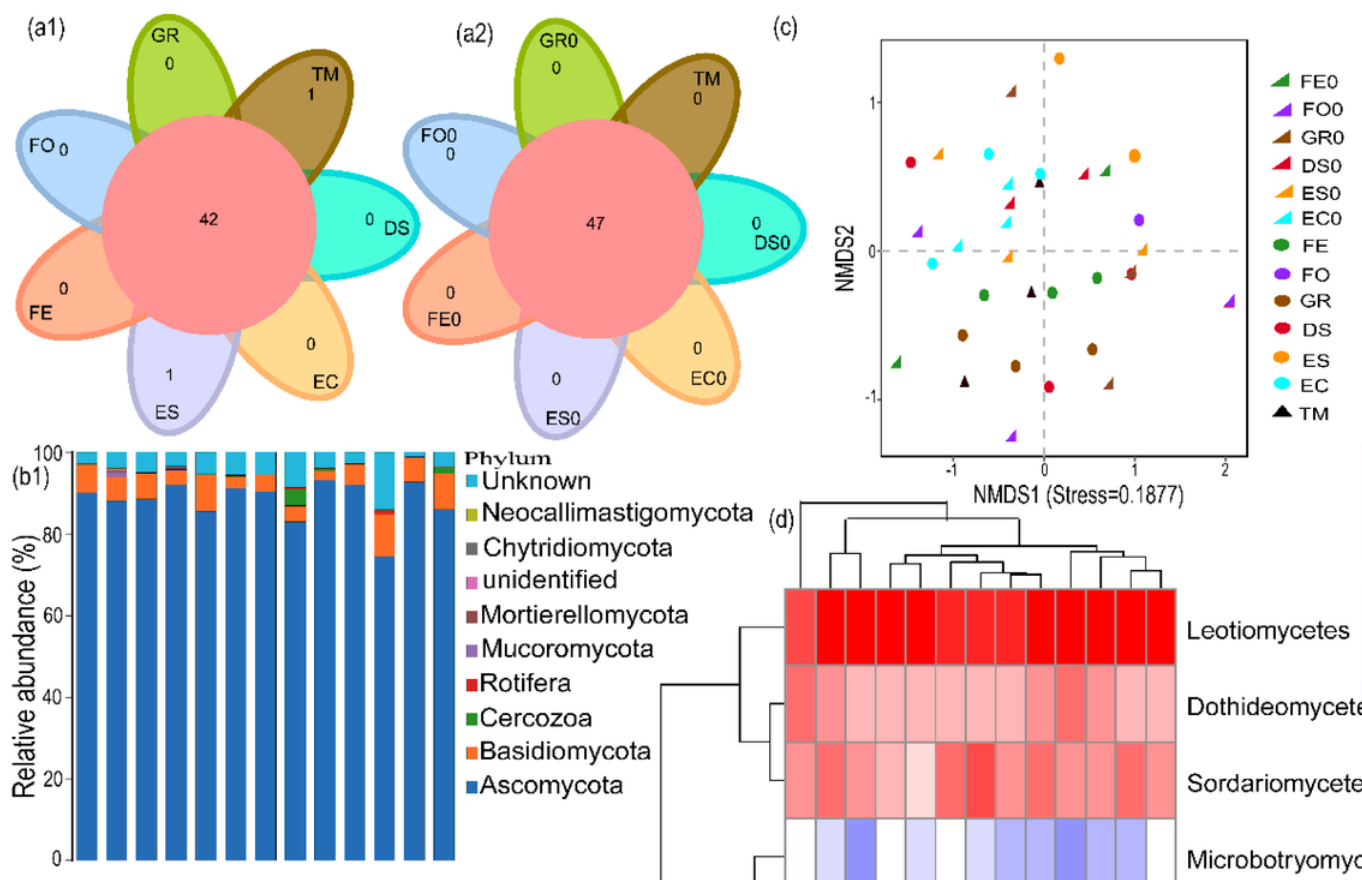

Phylum

NMDS1 (Stress $=0.1877$ )

Neocallimastigomycota (d)

- Chytridiomycota

nunidentified

-Mortierellomycota

- Mucoromycota

nRotifera

-Cercozoa

Basidiomycota

Ascomycota
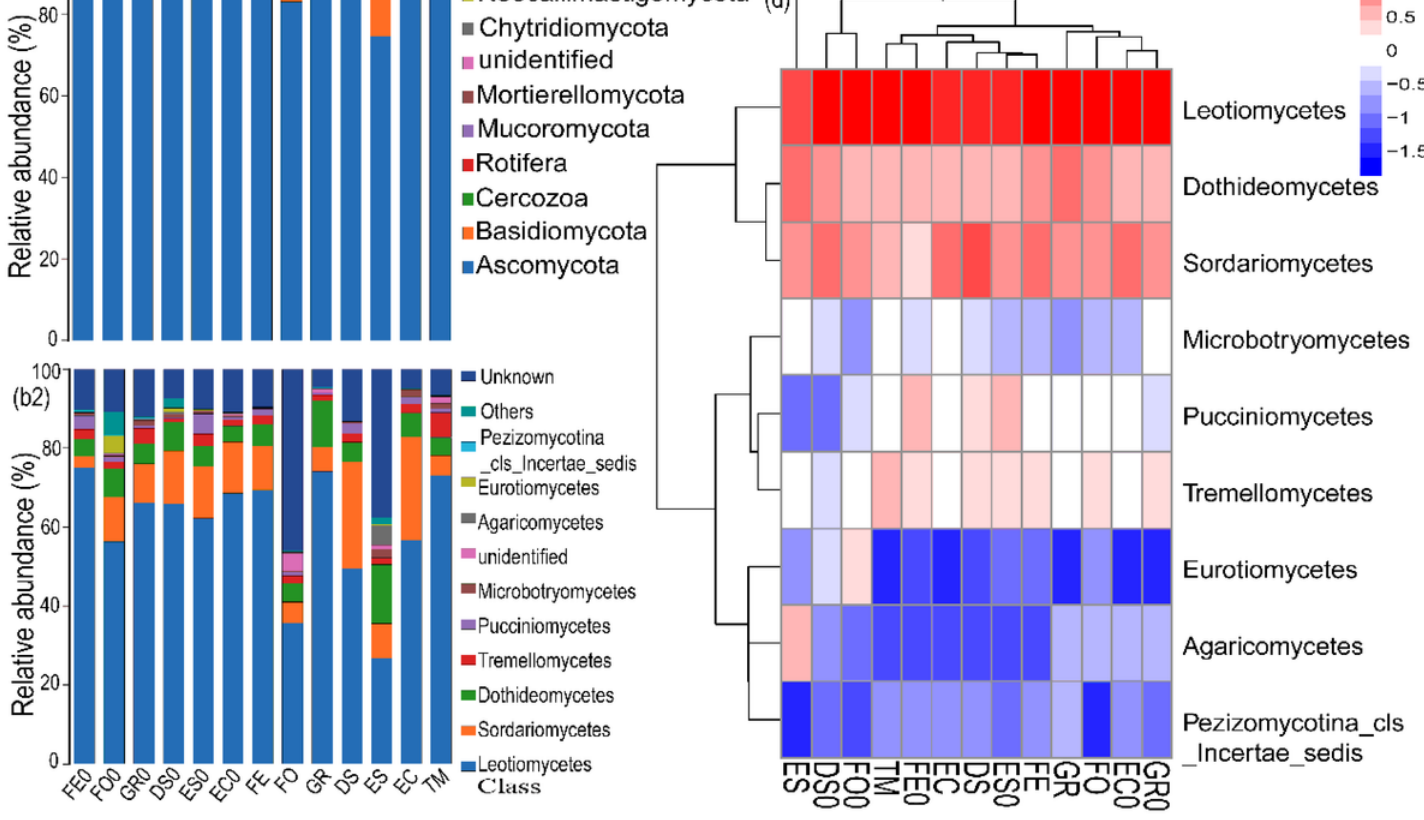

Figure 2

For fungi, a total of 42 shared fungal species were detected among the SPFG samples and TM, 1 unique species was detected in ES, and 1 unique species was found in TM, in addition to the shared species (Fig. 2a1). A total of 47 shared fungal species were detected among the SPFG-loss samples and TM (Fig. 2a2). The ANOSIM analysis showed that the similarity within the SPFG samples and TM (the R value for bacteria was 0.301 , and that for fungi was 0.423 ) was lower than that within the SPFG-loss samples and TM (the R value for bacteria was 0.084 , and that for fungi was 0.017 ) (Table 1). Furthermore, the NMDS plots indicated that the bacterial community structures in EC and ES and the fungal community structures in the ES differed from those in TM (Fig. 1c, Fig. 2c). 

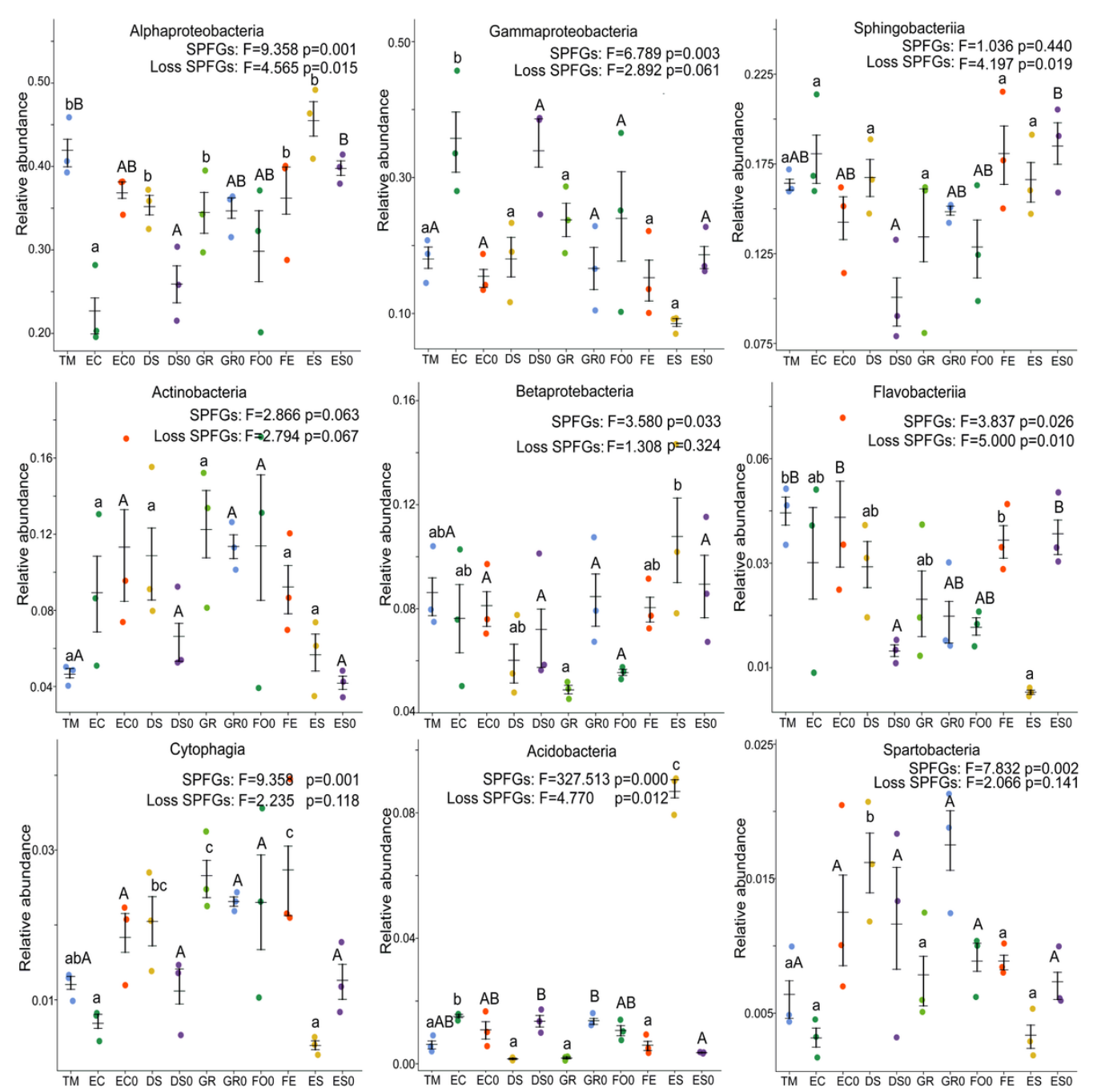

\section{Figure 3}

The relative abundances of Alphaproteobacteria, Gammaproteobacteria and Acidobacteria in EC, Flavobacteriia in ES, Cytophagia in GR and FE, and Spartobacteria in DS differed from those in TM (Fig. 3). In the SPFG-loss sample, the relative abundances of Alphaproteobacteria and Flavobacteriia in DSO were different from those in TM. 

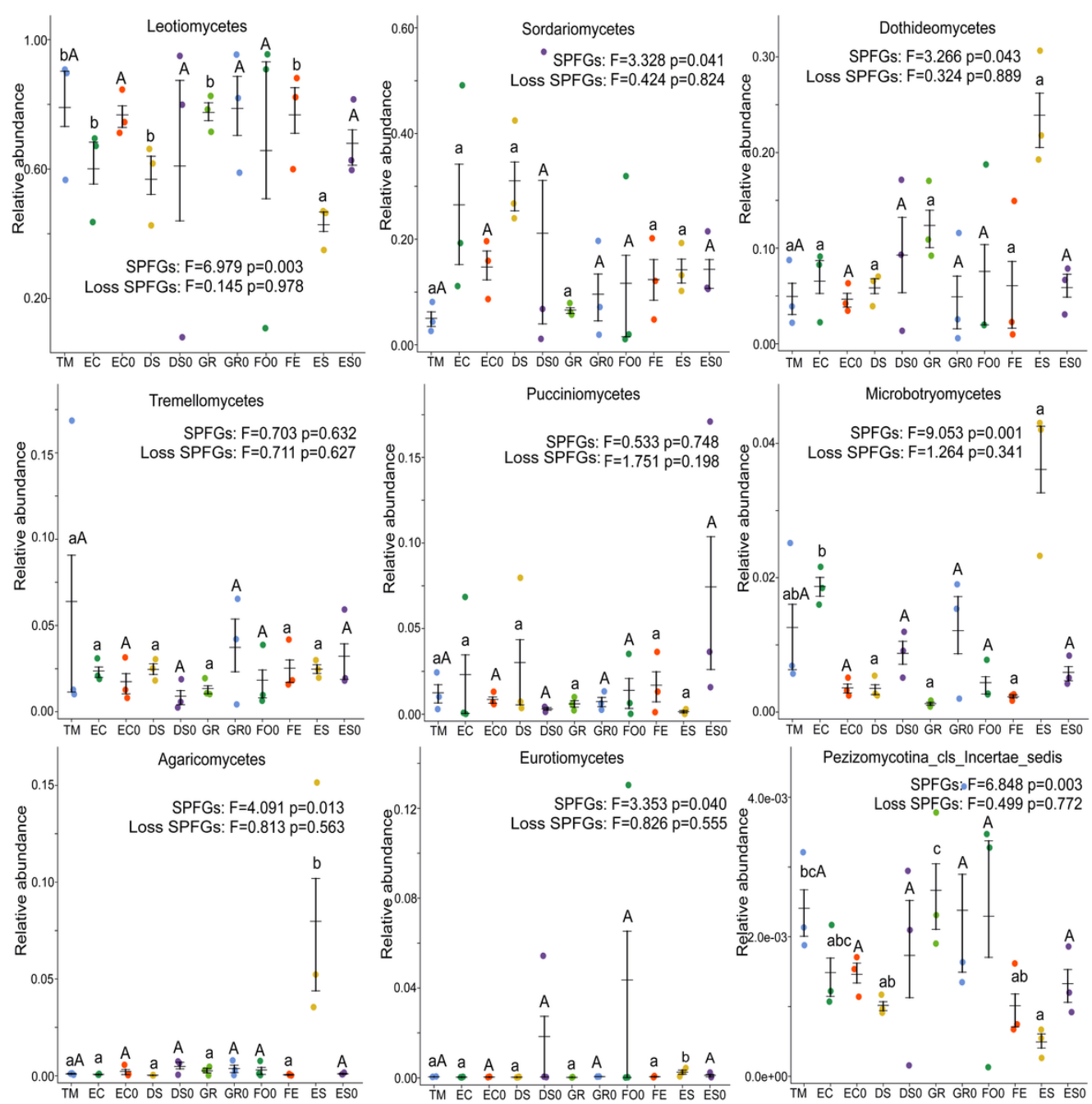

\section{Figure 4}

Specifically, ES differed from other SPFG samples (Leotiomycetes, Agaricomycetes and Eurotiomycetes); EC differed from other SPFG samples (Microbotryomycetes); GR differed from DS, FE and ES (Pezizomycotina_cls_Incertae_sedis); and Leotiomycetes, Agaricomycetes, Eurotiomycete and Pezizomycotina_cls_Incertae_sedis in ES were different compared with those in TM. However, there was no significant difference between any of the SPFGloss treatments and TM treatment (Fig. 4). 


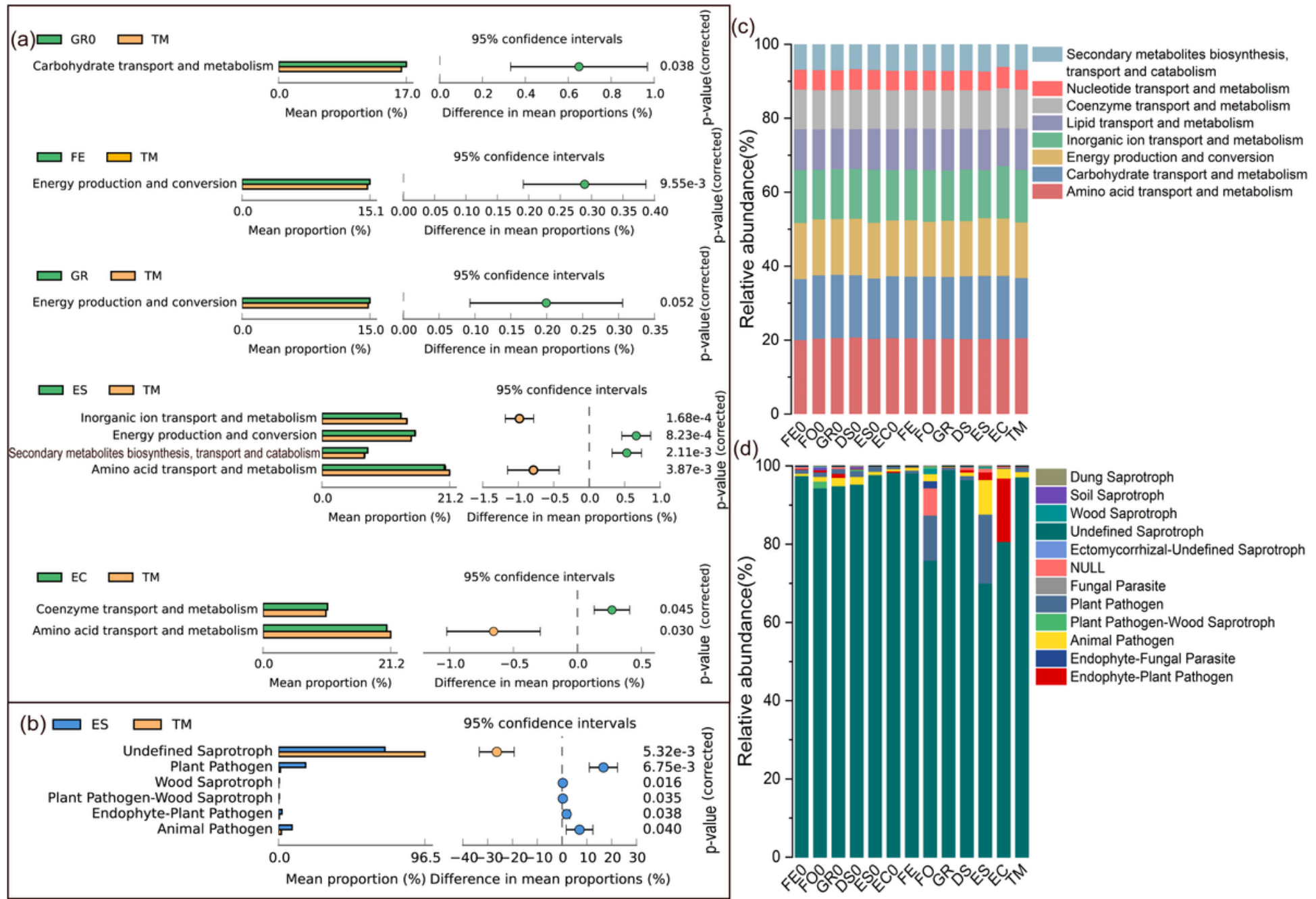

Figure 5

In this study, we identified eight metabolic functional pathways from bacteria. The most abundant functional pathway was amino acid transport and metabolism, followed by carbohydrate transport and metabolism and energy production and conversion, and the relative abundances of these three functional pathways reached over 50\% (Fig. 5c). Furthermore, the results of the t-test indicated that the proportions of metabolic functional pathways of FE, ES and EC were significantly different compared with those of TM, and in the SPFG-loss samples, only the proportions of carbohydrate transport and metabolism in GRO were higher than those in TM (Fig. 5a). 

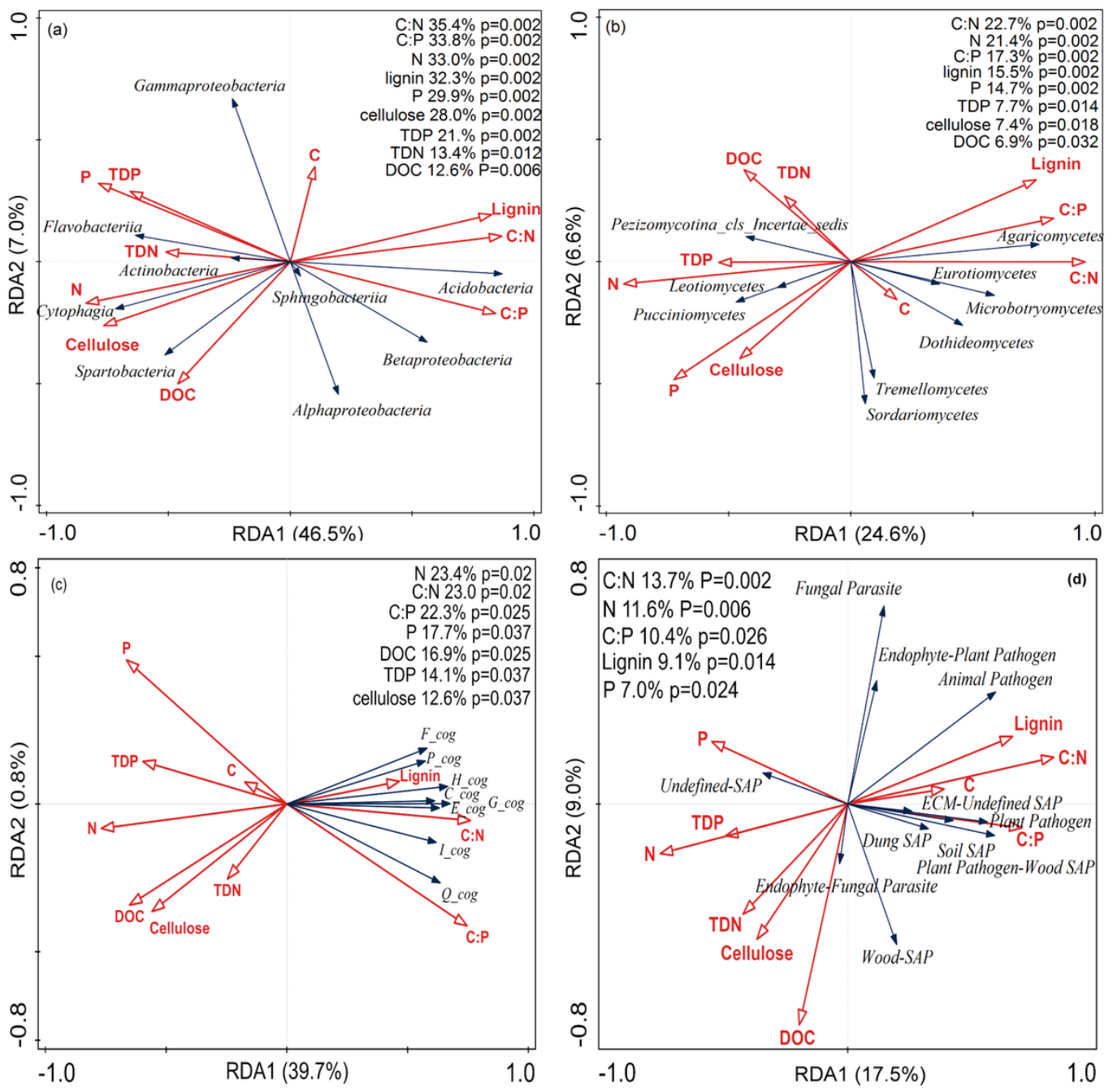

\section{Figure 6}

The Mantel test showed that the concentrations of $\mathrm{N}$, cellulose, and lignin and the ratios of C:N and C:P in litter were significantly correlated with the structures of the bacterial community (Table 3). The RDA results indicated that for the composition of bacteria, the first two axes explained $53.5 \%$ of the variability $($ RDA $\neg 1 \neg$, the $x$-axis for $46.5 \%$, and RDA $\neg \neg, \neg$ the $y$-axis for $7.0 \%$ ). The concentrations of the ratios of C:N and C:P, N, lignin, P, cellulose, TDP, TDN and DOC significantly influenced the bacterial community composition (Fig. 6a).

\section{Supplementary Files}

This is a list of supplementary files associated with this preprint. Click to download.

- Supplementarymaterial.docx 